\title{
Designing of innovative mining equipment for safe and successful work in mines
}

\author{
Vladimir Alexandrovich Trifonov ${ }^{1, a}$, Vladimir Nikolaevich Esaulov ${ }^{1}$, and Ekaterina Aleksandrovna Strekovtsova ${ }^{1}$ \\ ${ }^{1}$ Yurga Institute of Technology of Tomsk Polytechnic University, 652050 Leningradskaya str., 26, Yurga, Russia
}

\begin{abstract}
The article analyses contemporary problems of economic development in Russia. An innovative approach to designing of industrial products based on the assessment of their performance and economic characteristics makes it possible to develop, manufacture and operate products with an optimal quality-toprice ratio, which is a priority for the well-being of the country, oriented to import substitution. The authors define some ways to improve competitive abilities of mining equipment manufactured in Russia and estimate the prospects of economic development in short-term by the example of Kemerovo region and LLC "Yurginsky Machine Engineering Plant".
\end{abstract}

\section{Introduction}

Nowadays countries, corporations and companies, capable of foreseeing future development pathways, determine priority directions of economic growth, concentrate resources and gain the lead having advantages in global competition.

Numerous examples of that can be found in the world history: ups-and-downs of Russian economic development, overcoming the Great Depression in the USA, reconstruction of Europe after World War II, technological breakthrough in Japan and new industrial countries, recent development of China.

Today Russia is facing international sanctions, food embargo, drop in oil prices, decline of the rouble. A program of substituting imported goods with domestic alternatives is one of the ways to mitigate negative consequences of the economic crises.

Kemerovo region has chosen three priority paths of development: coal mining machinery manufacturing, agriculture, pharmaceutics. In this urbanized region, a great part of equipment used in the main industry (coal mining) is imported. So the substitution begins in coal industry.

Estimation shows that about $80 \%$ of equipment employed in mines is of foreign production. The reasons are clear. On the one hand, these are favourable credit conditions; on the other hand, this is a high quality of foreign product.

In addition, foreign suppliers were very skillful when offering equipment such as longwall complexes to Kemerovo miners. Having no shortage in money, they sold the equipment on the instalment plan, consumers paying for it after marketing the coal mined. Besides,

\footnotetext{
${ }^{\mathrm{a}}$ Corresponding author: v.trifonov64@rambler.ru
}

foreign engineers could maintain, improve and modernize the machinery daily during its performance in mines.

A complex of measures is being developed in the region. Today it is necessary to coordinate actions with foreign suppliers and Russian Technical Supervisory Authority. The parts of the imported equipment to be manufactured in Russia must be certificated. In the current economic conditions, both domestic and foreign suppliers are interested in that.

Such "combination" will probably take place on the basis of maintenance and service centres, which have been opened in the region by many foreign companies. Machine building companies of Kemerovo region could produce all necessary equipment to the order of the service centres. At the first stage it would be components and in two or three years they could produce the whole set of equipment. These tendencies are being studied within development economy [1-3].

The main efforts are being focused on transition to a model of economic development based on priority development of non-energy sector and innovations, import substitution and labor productivity growth, which will provide steady economic development and social stability in the period of unfavourable foreign economic and policy conditions.

\section{Results and Discussion}

Thus LLC "Yurginsky Machine Engineering Plant" (OOO "Yurmash") is able to produce original mining equipment as well as components for imported machinery and to be a growth leader of mining machines production. Having been involved in manufacturing of 
equipment for the fuel and energy industry since 1992, Yurginsky machine engineering plant has become recognized as an engineering centre for coal mining in Kemerovo region and one of the leading manufacturers of mining equipment in Russia.

Since 2006, the plant has been producing mining equipment of the international standard. In 2007, it enlarged its production capabilities with the help of its strategic partners: a Check producer of mining equipment $\mathrm{T}$ Machinery a.s. and a German company ESSER GmbH (in 2007). Now there are more companies in the list.

Possessing all functional characteristics adherent to foreign models machines produced by Yurginsky Machine Engineering Plant has a number of competitive advantages: lower exploitation costs, higher productivity, easy-to-maintain (Table 1).

Table 1. Mining Equipment manufactured by LLC "Yurginsky Machine Engineering Plant”.

\begin{tabular}{|l|l|}
\hline & $\begin{array}{l}\text { A wide range of powered roof supports of } \\
\text { various bearing capacities intended for } \\
\text { thin seam heights available for using in } \\
\text { plough and shearing mining systems, for } \\
\text { middle and thick seam heights, and face } \\
\text { end drift supports. }\end{array}$ \\
$\begin{array}{l}\text { A KPYU-50 roadheader is designed for } \\
\text { roadway development to mechanically } \\
\text { cave-in rocks and load cut debris in } \\
\text { horizontal. A cutting capacity is } 0,2 \text { to } 2,0 \\
\mathrm{~m}^{3} / \text { min. }\end{array}$ \\
$\begin{array}{l}\text { A narrow-web longwall shearer } \\
\text { "KUZBASS 500 YU" is designed for } \\
\text { fully mechanized cutting of coal in } \\
\text { working faces of fat and fat-slanted beds } \\
\text { with thickness from 1.6 to 4.8 m. Beds } \\
\text { should have natural interlayers with the } \\
\text { strength according to Protodiyakonov } \\
\text { scale of up to 4, aggregate capacity of up } \\
\text { to } 12 \% \text { of the seam thickness in the mines } \\
\text { hazardous for gas and dust. }\end{array}$ \\
$\begin{array}{l}\text { Narrow-web longwall shearer K750YU } \\
\text { narrow - web longwall shearers are } \\
\text { designed for fully mechanized coal } \\
\text { cutting in longwall faces in flat and steep } \\
\text { beds of a 1,4 ...4.0 m thickness and of up } \\
\text { to 35 degrees when a face is advanced to } \\
\text { the strike and to 12 degrees to the rise/dip, } \\
\text { coal resistance to cutting being equal up } \\
\text { to 360 kN/m. The shearers are capable to } \\
\text { operate in working environments having } \\
\text { intermediate rock layers, having } \\
\text { Protodyakonov hardness of up to } 4 \\
\text { aggregate capacity and less than 12\% of } \\
\text { the seam thickness. }\end{array}$ \\
\hline
\end{tabular}

Nowadays an innovative approach to product design is necessary to provide product competiveness, reliability and energy effectiveness. This approach must be based on technical solutions characterized by novelty, inventiveness, industrial applicability.

This factor is especially important for a steady longterm economic growth in any country. Consequently, certain conditions to support intensive innovative activity must be provided at the state level (financing fundamental and applied scientific researches) and at the level of market participants (close cooperation between scientific research institutes, universities and manufacturing enterprises).

Many companies create special risk capitals to master new trends and develop new products. They organize specialized subdivisions and working groups to develop technological policy at the highest level, departments coordinating innovative activity, project groups or product development centers, consulting and analytical groups, research and development departments responsible for innovations.

Based on the analysis of marketing strategies of Yurginsky Machine Engineering Plant it has been concluded that a new research and consulting department should be added into the company structure in order to increase efficiency of its innovative activity. It is a department controlling competitiveness of the company products - Product Competitiveness Control Centre (PCCC) (fig. 1).

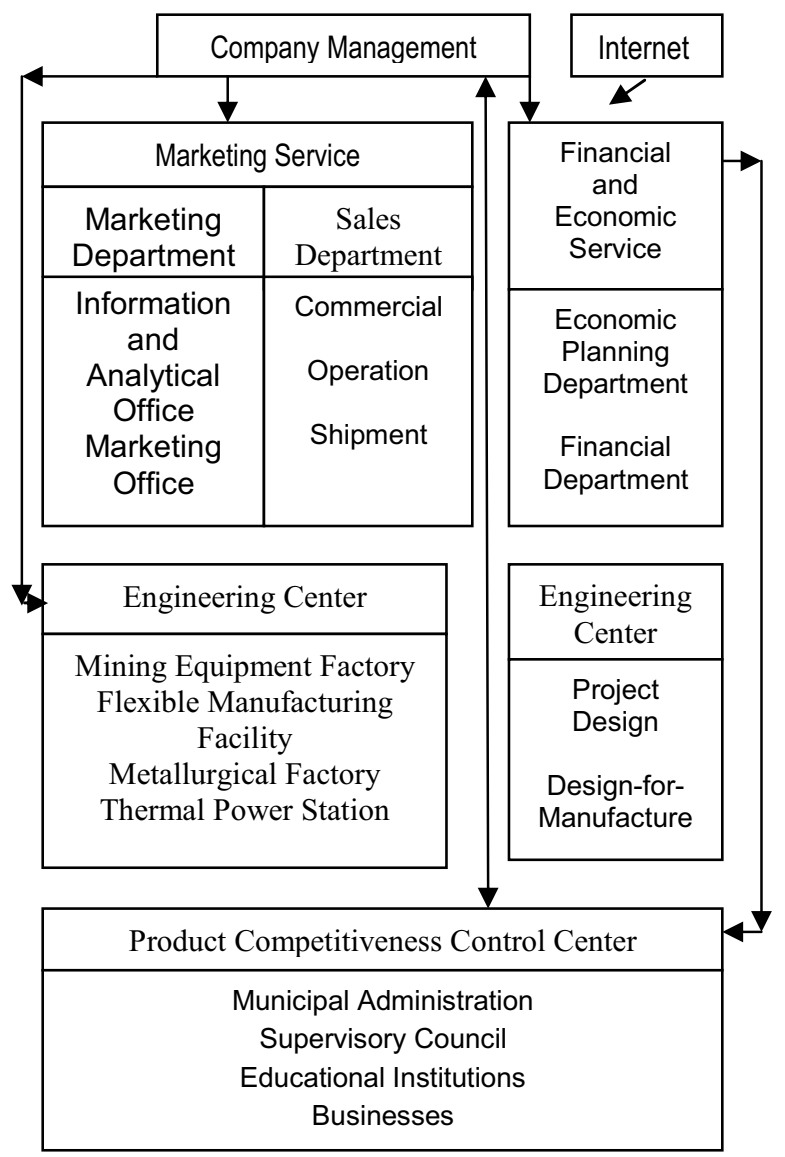

Fig. 1. Organizational structure of a machine building plant along with PCCC

PCCC has vertical links with the managing board, functional links with the Financial and Economic Service, Marketing Service, Engineering Centre and manufacture as well as informational links with external environment through the Internet.

PCCC staff should include specialists in technical expertise and compatibility forecast whose responsibilities are the following: 
1) determining directions, developing plans and programs, coordinating and controlling innovative activity of the company;

2) developing alternative solutions concerning own products, discussing ideas and estimating technical projects worked out by company subdivisions;

3) submitting proposals to the company management for making decisions and implementing technical and competitive policy.

Nowadays it is important and is stimulating to estimate operation characteristics of a designed product, that is, to correlate price and quality of the new product. A quality-to-price ratio of innovative items of the company's product range provides an ability of the product to compete with rival models. $(\mathrm{Cop}>\mathrm{Crp}>1)$, in other words, products commercialization must avoid price competition and base entirely on performance competition [5].

Innovations usually result from research-anddevelopment activity. It does not matter who carries out the research and development work - the manufacturer or a specialized company, institute, laboratory. A merchant who sells an innovative idea must be sure that the products, on which the idea is based, must be accepted by consumers, for whom the product is designed. Otherwise the innovations are risky. There are numerous examples of global companies suffering great losses caused by a wrong estimation of business ramifications of marketing innovative products. Adequate information available to the merchant guarantees risk reduction.

We suggest an approach to managing the process of designing innovative mining equipment based on monitoring of competitive abilities of own products and rival designs. It includes diagnostics of the product performance and economic characteristics, benchmarking and assessment of quality-to-cost ratio indexes as well as comparison of competitive ability levels. This leads to making decision on reengineering of the innovative mining equipment design process at each stage of its life cycle.

Alongside with conventional management functions (planning, organizing, motivating, controlling), we suggest the following innovative management functions: diagnosing, benchmarking, assessing and comparing competitive abilities of own innovative products and rival designs. If the competitive ability of own products is lower than that of the rival product, it is necessary to carry out reengineering.

Assessment and comparison of competitive abilities of one's own product and rival designs based on its performance and economic characteristics is carried out according to the pattern in Figure 2, which shows the management of the innovative mining equipment design process and includes:

1. Calculation and evaluation of quantity indexes of the competitive ability of own products (Cop) and of rival products ( $\mathrm{Crp}$ ) based on the technology factor, so called quality characteristics (QC).

2. Calculation and evaluation of quantity indexes of the competitive ability of own products and of rival products based on the economic factor, so called production and maintenance cost characteristics (CC).

3. A ratio of quality characteristics and production cost characteristics determines a ration of competitive ability of own products (op) and rival products (rp).

With equal quality characteristics (QCop $=$ QCrp) the product characterized by the lower production and maintenance cost has a competitive advantage, i.e. if CCop < CCrp, then (QC/CC)op > (QC/CC)rp.

When the competitive ability of own products is higher and sales opportunities are great, the managers of PCCC continue searching for compatible innovations in order to keep up a high competitive level and sales performance.

When the competitive ability of own products is lower and sales opportunities are worse than those of the company's competitors, the managers take over reengineering functions [6]. These innovative management functions should be performed at all management stages.

Innovative management based on new competitive products depends on a time factor. Thus, effective innovative management is possible only through application of automated tools, which provide correlation, and alignment of technological operations throughout decades.

Let us analyse how the cost/quality criterion works by the example of a certain innovative product. The plant is developing a direct electrical drive with intellectual control SAEP-275/ for "KUZBASS 500M" longwall shearer cutter.

We have analysed support units of direct electrical drive SAEP-275/3300. SAEP-275/3300 support units are devices designed to provide a prescribed motion with a specified reliability and load capacity. Depending on the friction character, there are two types of support units: sliding friction units (steel-bronze, fluorine plastic-4 and the like), rolling friction units (ball bearing or roller bearing support units).

The support units design stipulates performance characteristics of SAEP-275/3300 and manufacturing costs and thus influences their price. The choice of a support unit of SAEP-275/3300 depends on an available technology and manufacturing capabilities. To choose a proper support unit, it is required to develop an operation model of SAEP-275/3300 with the following performance characteristics (Table 2).

Using this model one can do necessary calculations and determine the optimal price (Table 3 ).

The following is required for designing the model:

1) Limit values of manufacturing costs $(\mathrm{Cm})$ and operating costs $(\mathrm{Co})$ and performance characteristics indexes Pdn, Cdb, Psb, Csn (Table 4);

2) Demand and supply of elasticity, which characterize relative changes in the market;

3) A software for calculation of values by means of Excel electronic spreadsheets with input curves of consumers demand and manufactures supply capabilities. 
Table 2. Comparative characteristics of support units.

\begin{tabular}{|c|c|c|}
\hline Type of a support unit & $\begin{array}{c}\text { Sliding friction } \\
\text { support units } \\
\left(\mathrm{S}_{1}\right)\end{array}$ & $\begin{array}{c}\text { Rolling } \\
\text { friction } \\
\text { support } \\
\text { units }\left(\mathrm{S}_{2}\right)\end{array}$ \\
\hline Direction precision $\mathrm{P}_{\mathrm{d}}$ & 1 & 2 \\
\hline Friction torque $\mathrm{T}_{\mathrm{f}}$ & 3 & 2 \\
\hline Thermal insensitivity $\mathrm{Ins}_{\mathrm{th}}$ & 0 & 1 \\
\hline Load capacity $\mathrm{L}$ & 2 & 3 \\
\hline Wear resistance $\mathrm{R}_{\mathrm{w}}$ & 0 & 1 \\
\hline Vibration resistance $\mathrm{R}_{\mathrm{v}}$ & 1 & 1 \\
\hline & $\sum \ni_{1}=7$ & $\sum \ni_{2}=10$ \\
\hline
\end{tabular}

Table 3. Aggregated costs (C) depending on a type of support units.

\begin{tabular}{|c|c|c|c|}
\hline Design & $\begin{array}{c}\text { Manufact } \\
\text { uring } \\
\text { costs } \\
\left(\mathrm{C}_{\mathrm{m}}\right), \$\end{array}$ & $\begin{array}{c}\text { Operating } \\
\text { costs }\left(\mathrm{C}_{\mathrm{o}}\right), \\
\$\end{array}$ & $\begin{array}{c}\text { Aggregated } \\
\text { costs }(\mathrm{C}), \$\end{array}$ \\
\hline $\begin{array}{c}\text { 1. Sliding friction } \\
\text { support units }\end{array}$ & 6 & 4 & 10 \\
\hline $\begin{array}{c}\text { 2. Rolling friction } \\
\text { support units }\end{array}$ & 8 & 4 & 12 \\
\hline
\end{tabular}

Table 4. Limit values of costs $\mathrm{Cdb}$, Csn and performance characteristics Pdn, Psb.

\begin{tabular}{|c|c|c|c|c|}
\hline Limit values Designs & $\ni_{d}{ }^{\mathrm{n}}$ & $\ni_{s}^{\mathrm{b}}$ & $3_{\mathrm{s}}{ }^{\mathrm{n}}$ & $3_{d}{ }^{\mathrm{b}}$ \\
\hline $\begin{array}{c}\text { 1. Sliding friction support } \\
\text { units }\end{array}$ & 2 & 7 & 3 & 10 \\
\hline $\begin{array}{c}\text { 2. Rolling friction support } \\
\text { units }\end{array}$ & 5 & 10 & 5 & 12 \\
\hline
\end{tabular}

Calculation of performance characteristics $\mathrm{Pd}$, Tf, Insth, $\mathrm{L}, \mathrm{Rw}, \mathrm{Rv}$ for each type of support units $(\mathrm{S} 1 \div \mathrm{S} 2)$, performance characteristics $\sum \mathrm{P} 1-2$, manufacturing costs Cm1-2, operating costs Co1-2 and aggregated costs (C) gives comparative characteristics of support units in terms of dollar value, sum values of operating characteristics, manufacturing and operating costs $\mathrm{Cm}$ Co, aggregated costs (C).

\section{Conclusion}

In the competitive market, business advantages belong to the economic entity, which produces products with the best ratio of performance and economic characteristics and the price. It stimulates producers to improve the product quality and minimize price.

For a SAEP-275/3300 design with "steel-bronze" support units, aggregated manufacturing and operating costs are lower than those for SAEP-275/3300, different types of support units, but the product quality is lower as well. Alternative SAEP-275/3300 designs, characterized by higher load capacity, good wear resistance and lower losses, cost $1.5-2$ times as much as SAEP-275/3300 with sliding friction supports.

The presented determined and formalized approach to the process of design of SAEP-275/3300 by the example of analyses of its performance and economic characteristics gives a unique opportunity to develop, manufacture and operate products with the optimal quality-to-price ratio.

In this case consumers get a ready-to-use reliable product with required operating characteristics, relatively low price and less operating costs within the time frame promised. It is important that the product is safe and successful for work in the mines. As science and technology develop, people acquire new needs. To meet these needs new pioneering products are being designed $[7,8]$.

Producers obtain the required operating characteristics of their products, which provide competitive advantage in the market and the highest profit without dramatic change in technology as well as expanding the market for their goods, increasing market share and sales.

Therefore, the results of the research in modelling the development process of innovative mining equipment can serve as the basis for further improvements in machine engineering enterprise management. They are of interest for federal, regional and municipal authorities when correcting innovative policies, working out development strategies, defining procedures for monitoring of innovative activity. It requires mobilization of all reserves and resources, increasing management efficiency at all levels including enterprise.

\section{References}

1. D. Acemoglu, J. A. Robinson, Crown Business (2012)

2. D. Acemoglu, S. Johnson, J. Robinson, Handbook Of Economic Growth, Volume (2005)

3. E. Malesky, Panel on Institutions and Transition (2000)

4. J.L. Bower, C.M. Christensen, Harvard Business Review (1995)

5. C. Hart, Harvard Business Review (1988)

6. J. Campy, M. Hammer, HarperBusiness (1993)

7. A.H Maslow, Harpaer \& Row (1954)

8. V. A. Trifonov, S. V. Grichin, M. A. Kovaleva, Applied Mechanics and Materials (2014) 